\title{
Innovative learning design: Experiences from gadget workshops in business informatics classes
}

\section{Jäger, Janine ${ }^{\text {a }}$; Korkut, Safak ${ }^{\mathrm{a}}$ and Dornberger, Rolf ${ }^{\mathrm{a}}$}

${ }^{a}$ Institute for Information Systems, School of Business, University of Applied Sciences and Arts Northwestern Switzerland, Switzerland.

\begin{abstract}
The short paper introduces and discusses the concept of a workshop for students of the Bachelor of Science in Business Information Technology study program at the University of Applied Sciences and Arts Northwestern Switzerland, based on theoretical aspects of the experiential learning theory as well as Design Thinking. The goal of the workshop was to enhance the learning outcome of students of this practice-oriented study program. The paper proposes drivers of change for experience-oriented teaching methods as well as reflects on the experiential learning theory and design thinking approaches in education for our case, followed by an elaborate description of the conducted workshops and a discussion of the respective outcomes and experiences. The paper emphazises the observational insight, that learning from active experience as well as through creative tasks should help enhancing cognitive competencies through the application and further development of imparted topical knowledge. The presented gadget workshop aimed at increasing engagement and motivation in the respective class and, as a result of observations, enabled further research on student learning as well as course-relevant practical class activitites.
\end{abstract}

Keywords: experiential learning, business informatics, design thinking, gadget workshop 


\section{Introduction}

In our complex, dynamic and fast changing world, which is getting more and more digitalized and technologically advanced, there is an urgent need to reinforce the educational focus on cultivating competencies and skills that help dealing with complexity and change rather than having a main focus on pure fact-driven knowledge.

Our students are surrounded by tools and toys of the digital age, such as mobile phones and smart gadgets (Prensky, 2001). These artifacts of the digital world connect them with information, but also enable them to experience, think and reflect on the new perspectives and potentials of business information systems. On the basis of observations and experiences the authors claim that students need to be actively involved in learning design, information gathering and interpretation, knowledge creation and reflection of their own learning process. Especially in higher education at universities and in practice-oriented study programs (e.g. Information and Communication Technology (ICT) study programs) there should be an increased focus on encouraging collaboration, reflection, problem solving, agility, idea creation and creativity in students. Hence, the role of a teacher in the digital age, where information is available everywhere and all the time, shifts towards being a mentor and coach in the learning process and giving inspiration and guidance to prepare students for the job market.

The authors regard students as active drivers of their learning process, not merely as receivers of input, which should be inspired and supported in developing competencies through experience learning, especially in the practice-oriented field of business informatics. The paper presents and discusses a workshop class design based on the experiential learning theory and Design Thinking in a practice oriented Bachelor of Science in Business Information Technology study program.

\section{Theoretical Background}

According to the Horizon Report Higher Education it is increasingly important to promote active learning where the "typical podium is moved from the front of the classroom to the center" (Johnson et al., 2015, p. 18) and to provide a learning environment "that fosters experimentation, curiosity and above all, creativity" (p. 22).

According to Johnson et al. (2015) it is important that skills needed in the real world must be identified and promoted through informal learning and teaching methods. Furthermore, it is of high importance to improve digital literacy, hence the holistic understanding of digital tools and information. Also the flipped classroom model is emphasized by Johnson et al. (2015) as a future trend in higher education, where more active and project-based learning is the main activity in the classroom and pure knowledge acquisition is shifted outside of the classroom. Johnson et al. (2015) introduce the trend of makerspaces in higher education, which describes "workshops that offer tools and the learning experiences needed to help people carry out their ideas" (p. 40). Therefore, an "openness to experiment, iterate 
and create is needed" (p. 40). The maker space trend stems from the movement of innovative entrepreneurs and designers.

The authors combine the theory of experience learning and aspects of design thinking to design educational workshops in business informatics modules with the goal to enhance the learning outcome and promote the active application of the imparted knowledge and developed skills in the study program.

\subsection{Experiential learning}

The Experiential Learning Theory (ELT) describes learning as a process in which knowledge is created through the transformation of experience and reflection (Kolb and Kolb, 2008). The experiential learning process undergoes four stages, which are experiencing, reflecting, thinking and acting (McLeod, 2013). According to Kolb and Kolb (2008) the basis for experiences are observations and reflection, which can then be transformed into abstract concepts for new implications and action. Furthermore, the importance of conversation for reflection and deriving meaning from experiences is being emphasized for improving the learning outcome and making experiential learning more effective.

Experience learning addresses the higher levels of the Bloom Taxonomy, where new ideas are derived from existing knowledge and unrelated parts (Cannon and Feinstein, 2005). Cannon and Feinstein (2005) state that "experiential learning involves immersing learners in an environment in which they actively participate in acquiring knowledge" (p. 349). They argue that experiential learning challenges students through prototypic and complex situations, which is also represented in the higher levels of the well-known Bloom Taxonomy of learning objectives.

\subsection{Design Thinking}

"Design thinking is at its best if tangible prototypes can be used to capture and validate end user needs and envision new products and services" (Gabrysiak et al. in Plattner et al., 2011, p. 219). The creation of software or product prototypes is the main goal of most design thinking projects or workshops. Thereby, people and their interdisciplinary and creative interaction are the core of the process. In order to create innovative ideas and prototypes for software or technological products, mockups are created which serve as a basis for discussion and the identification of innovative solutions (Gabrysiak et al. in Plattner et al., 2011).

In education, design thinking can support students in developing meta competencies and create a more holistic learning experience and reflection on learning (Scheer et al., 2012). Scheer et al. state (2012) that learning is achieved "through the interaction with the object and its context" and suggest Design Thinking as methodology to design learning experiences in order to bridge the gap between theory and practice. The adapted class design should have a good "balance between instruction and construction" and provide 
diverse possibilities for experiencing and reflection (Scheer et al., 2012). The main stages following the design thinking approach are: observations, frameworks, imperatives and solutions (Beckmann and Berry, 2007).

\section{Design of the Gadget Workshop}

The focus of the workshop in the Bachelor of Science in Business Information Technology study program has been on creating business ideas for gadgets that are so far mostly used in the game industry, such as Samsung Gear VR (Samsung, 2014a), Leap Motion infrared controller (2013), Sphero 2.0 App-enabled Robotic Ball (2013), MYO Gesture Control Armband (2013) and Google's Project Tango tablet (2015). The selection of gadgets is a representation of the commercially-available, innovative and trending technologies in the digital market and of associated Information Technology (IT) components. Especially virtual reality gadgets such as Samsung Gear VR virtual reality headset aim at progressively changing the way we interact with mobile technologies (Samsung, 2014b). Leap motion and MYO Gesture Control Armband are both introducing new humancomputer interaction oppurtunities as an alternative to common peripherials such as keyboard and mouse. Sphero 2.0 is a programmable robot ball which can be controlled by a smartphone or a tablet. Project Tango is a mobile tablet device for developers which is enriched by a set of sensors that support high precision tasks such as motion tracking, depth precision and area learning. All these gadgets inspire scholars to research and develop projects for innovative man-machine interaction approaches for specific use cases (Lange et al., 2000; Mendez-Zorilla et al., 2015; Wachs et al., 2011; Whyte, 2010).

In the workshop the students' task was to be creative and apply their knowledge and skills in order to develop ideas and mockups for business concepts based on the experience and testing of gadgets as well as the exchange and reflection on the respectively developed ideas. Innovative start ups and their often agile, flexible and interactive approach towards idea and product creation served as an example in order to design the different phases of the competency based workshop which made use of technology in order to inspire ideas and creative thinking.

The workshop has been divided into six parts (Table 1):

1) Factual and inspirational input on innovative technologies and gadgets:

An initiating presentation focused on giving factual input, inspiration and the introduction of the gadgets applied in the workshop. Devices from famous science fiction movies and how those inspired today's technological developments were shown. Drawing connections from science fiction movie technology from movies such as Star Trek (Roddenberry and Berman, 1987-1994), Back to the Future Part II (Zemeckis and Spielberg, 1989) and Knight 
Rider (Larson and Foster, 1982) intended to motivate the students to think creatively and without boundaries, because all technologies start with an idea.

2) Gadget testing under given parameters:

Following a short instruction on how to operate the gadgets, the students were invited to test and play freely with the devices. The gadgets included a virtual reality goggle (Samsung Gear VR, 2014), an infrared controller (Leap Motion, 2012), a Bluetooth controlled robotic ball (Sphero 2.0, 2013), a muscle controller (Myo Connect, 2013) and a mobile 3d technology tablet (Project Tango, 2015). The focus of this phase was on the active experience with each gadget and the creation of respective business application ideas.

3) Group discussion and idea collection:

In the group discussion phase the students had the task to transfer their business ideas for the gadgets into sketches or mockups. The aim of this group work was to connect existing knowledge and the experience from the gadget testing and transfer those into business ideas. In this phase the idea sketches were supposed to be in an abstract state with a focus on the reflection and conceptual transformation of the experience.

4) Group discussion and idea selection:

In this phase the previously formed student groups were consolidated into extended groups. Each group had the task to pitch their ideas to the other students and then collectively decide on one final idea per group with the most potential for a business case. The students had to actively discuss and reflect on the proposed ideas, apply their knowledge and practice communication and negotiation skills.

5) Conceptual prototyping:

In this phase, the groups worked on finalizing the concept for their chosen business idea for the tested gadgets and sketch the results and main aspects on a flipchart for the presentation. Hence, the students had to work out a proper storyline for the key facts of their concepts for the presentation in a short time. During this phase, the application of knowledge as well as presentation skills were demanded.

6) Concept presentation and discussion:

In the final workshop phase a chosen representative of each group presented the developed concepts to the other participants and the lecturers. In the discussion panel the concepts were constructively discussed and feedback was given with a focus on the reflection of the working process. 
Table 1. Stages of the gadget workshop in business informatics classes

\begin{tabular}{|c|c|c|c|}
\hline & Stages of the Workshop $(\mathrm{N}=20)$ & Experiential Learning & Innovation Process \\
\hline 1 & Input (30 minutes) & & \\
\hline 2 & $\begin{array}{l}\text { Gadget Testing (1hour) } \\
\qquad \quad 5 \text { Gadgets } \\
\text { - } 4 \text { Groups (of } 5 \text { students) }\end{array}$ & $\begin{array}{l}\text { Concrete Experience } \\
\text { (Experiencing) }\end{array}$ & $\begin{array}{l}\text { Observations } \\
\text { (Context, } \\
\text { information } \\
\text { gathering) }\end{array}$ \\
\hline 3 & $\begin{array}{l}\text { Group Discussion and Idea } \\
\text { Collection ( } 30 \text { minutes) } \\
\qquad \quad 4 \text { Groups (of } 5 \text { students) }\end{array}$ & $\begin{array}{l}\text { Reflective } \\
\text { Observation } \\
\text { (Reviewing, } \\
\text { Reflecting) } \\
\end{array}$ & $\begin{array}{l}\text { Frameworks } \\
\text { (Insights, } \\
\text { processing } \\
\text { information) }\end{array}$ \\
\hline 4 & $\begin{array}{l}\text { Group Discussion and Idea Selection } \\
\text { (30 minutes) } \\
\text { - } 2 \text { Groups (of } 10 \text { students) }\end{array}$ & $\begin{array}{l}\text { Abstract } \\
\text { Conceptualization } \\
\text { (Concluding, } \\
\text { Learning) }\end{array}$ & $\begin{array}{l}\text { Imperatives } \\
\text { (Ideas, } \\
\text { convergence) }\end{array}$ \\
\hline 5 & $\begin{array}{c}\text { Conceptual Prototyping (30 minutes) } \\
\qquad \quad 2 \text { Groups (of } 10 \text { students) }\end{array}$ & $\begin{array}{l}\text { Active } \\
\text { Experimentation } \\
\text { (Planning, } \\
\text { Implementing) }\end{array}$ & $\begin{array}{l}\text { Solutions } \\
\text { (Experiences, } \\
\text { concretization) }\end{array}$ \\
\hline 6 & $\begin{array}{l}\text { Presentation of Concept and } \\
\text { Discussion (30 minutes) } \\
\qquad \quad 2 \text { Groups (of } 10 \text { students) }\end{array}$ & & \\
\hline
\end{tabular}

\section{Discussion and Outlook}

From the experience of the authors the integration of a workshop at the end of the semester in the practice-oriented class in the Bachelor of Science in Business Information Technology led to active engagement of the students and the application of as well as the reflection on the content learned in class. The authors suggest that the workshop class design can also partially serve as exam preparation through the active recall and application of the knowledge learned throughout the semester.

The authors emphasize the importance of precise instruction for the different stages of the workshop with regards to timing and form of the expected outcomes in order to provide a framework and secure sandbox for the students' experience as well as the application and testing of the students' competencies. As experiential learning theory suggests, the phases of experiencing, reflecting, thinking and acting were followed during the workshop and led to a transformation of knowledge and experience into creative and innovative business ideas. Based on observations and oral student feedback it is being assumed by the authors that the experiential learning approach made a contribution to help the students in bridging the gap between the theoretical knowledge acquired in class and practice.

The workshop resulted in disruptive and creative ideas (Figure 1) that originated from and were developed through collaborative work and the active discussion and brainstorming of 
the students in various stages of the workshop. The developed ideas will be the basis for further research in student papers and theses.

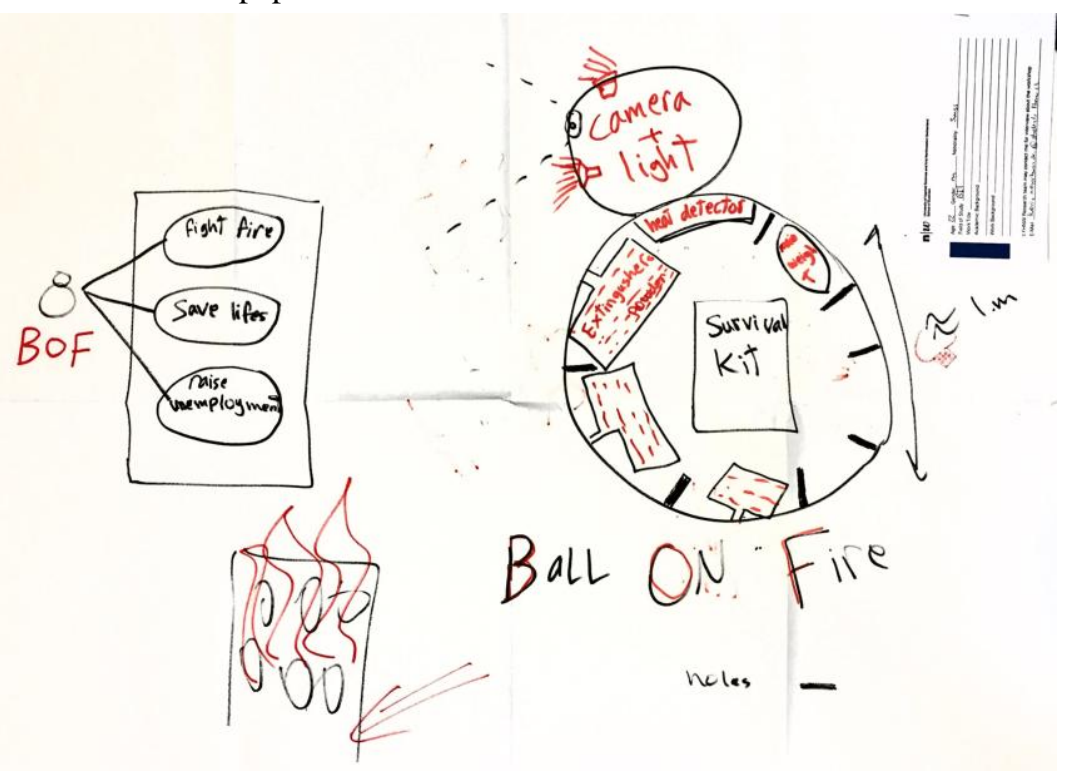

Figure 1: A sketched result from the workshop. Ball on Fire, Sphero 2.0 as a life saver unit.)

In order to verify the authors' assumption that the application of experiential learning and Desing Thinking methodologies in practice-oriented study programs, especially in the field of technology, leads to enhanced learning outcomes, further research as well as quantitative studies need to be conducted. The authors plan to conduct further workshops in practiceoriented study programs and to set up experiments in order to investigate the impact on exam results respectively learning outcomes in a structured approach. Additionally, the further development of the workshop concept and its application in other practice-oriented study programs is intended.

\section{References}

Beckmann, S.L. \& Barry, M. (2007). Innovation as a Learning Process: Embedding Design Thinking. California Management Review, 50(1).

Cannon, H. M., \& Feinstein, A. H. (2014). Bloom beyond Bloom: Using the revised taxonomy to develop experiential learning strategies. Developments in Business Simulation and Experiential Learning, 32, 348-356.

Johnson, L., Adams Becker, S., Estrada, V., and Freeman, A. (2015). NMC Horizon Report: 2015 Higher Education Edition. Austin, Texas: The New Media Consortium. Retrieved from http://cdn.nmc.org/media/2015-nmc-horizon-report-HE-EN.pdf

Kolb, A. Y., \& Kolb, D. A. (2005). Learning styles and learning spaces: Enhancing 
experiential learning in higher education. Academy of management learning \& education, 4(2), 193-212.

Lange, B., Chang, C. Y., Suma, E., Newman, B., Rizzo, A. S., Bolas, M. (2011). Development and evaluation of low cost game-based balance rehabilitation tool using the Microsoft Kinect sensor." in Proc. Annu. Int. Conf. IEEE Eng. Med. Biol. Soc., 2011, pp. 1831-1834.

Larson, G., \& Foster, R. (Producers). (1982). Knight Rider. TV Series. United States: NBC.

Leap Motion (2013). Leap Motion. Retrieved from https://www.leapmotion.com/product

Mendez-Zorrilla, A., Garcia-Zapirain, B., Eskubi-Astobiza, J., Fernández-Cordero, L. (2015). Sphero as an Interactive Tool in Computer Games for People with ID. Computer Games: AI, Animation, Mobile, Multimedia, Educational and Serious Games (CGAMES), 2015, pp. 99-102.

McLeod, S. A. (2013). Kolb - Learning Styles. Retrieved from www.simplypsychology. org/learning-kolb.html

Plattner, H., Meinel, C., \& Leifer, L. (Eds.) (2011). Design-Thinking. Understand-ImproveApply. Heidelberg: Springer.

Prenksy, M. (2001). Digital natives, digital immigrants. On the Horizon. Vol 9(5). MCB University Press: United Kingdom.

Project Tango Tablet (2015). Retrieved from https://www.google.com/atap/project-tango/ hardware/

Roddenberry, G., \& Berman, R. (Producers). (1987). Star Trek: The Next Generation. Motion picture. California: Paramount Domestic Television.

Samsung Gear VR (2014a) Retrieved from http://www.samsung.com/ch/microsite/gearvr/

Samsung. (2014b). Samsung Explores the World of Mobile Virtual Reality with Gear VR. Retrieved from http://www.samsungmobilepress.com/2014/09/03/Samsung-Exploresthe-World-of-Mobile-Virtual-Reality-with-Gear-VR-1

Scheer, A., Noweski, C., \& Meinel, C. (2012). Transforming constructivist learning into action: Design thinking in education. Design and Technology Education: an International Journal, 17(3).

Sphero Robotic Ball (2013). Retrieved from http://www.sphero.com/

Thalmic Labs (2013). MYO - The Gesture Control Armband. Retrieved from https://www. thalmic.com/myo/

Wachs, J. P., Kölsch, M., Stern, H., Edan, Y. (2011). Vision-based hand-gesture applications. Communications of the ACM, 54(2). [doi>10.1145/1897816.1897838]

Whyte, J. (2010) Innovation and users: virtual reality in the construction sector. Construction Management and Economics, 21:6, 565-572. DOI: $10.1080 / 014461903200$ 0113690

Zemeckis, R. (Director), \& Spielberg, S. (Producer). (1989). Back to the future part II. Motion picture. United States: Universal. 